\title{
Study and Computational Simulation of Nanomaterial Coating to Reduce Crevice Corrosion
}

\author{
Jeremy Li
}

University of Bridgeport

\begin{abstract}
The crevice correction is a common type of localized corrosion which costs multibillion dollar losses in many different fields including aerospace, automobile, and building structures. The crevice geometry can easily catch moisture and impurity which accelerates the chemical corrosion. It is one of the dangerous corrosions that can cause sudden failure of the products and involve the human injury in some cases. Nanomaterial coating can disperse extremely tiny platelets into the crevice geometrical surfaces and make much strong and durable material coating to significantly reduce the crevice corrosion. This paper focuses on reducing the crevice corrosion damage by introducing the computer-aided modeling and simulation of nanomaterial coating on crevice structure to verify the nano-coating performance. The sample experiment to prove the strong anti-corrosion of nano-coating on crevice structure has also been performed to compare with the computational simulation results. Both results show that the nano-coating has much strong anti-corrosion performance over currently existing anti-corrosion coating techniques.
\end{abstract}

Keywords Crevice Corrosion, Nano-Coating, Computational Simulation, Anti-Corrosion, Cost-Saving,Nanotechnology

\section{Introduction}

Crevice corrosion is a localized corrosion that can happen in some good anti-corrosion materials including stainless steel[1]. This type of corrosion could not be easily to be detected at the early stage of the corrosion due to its invisible areas[2]. Because of this reason, sometime the products can have sudden malfunction and cause catastrophic failures which even can lead human injury[3]. The crevice geometry can easily catch and trap the moisture and chemical pollutes that speed up the corrosion process[4]. Crevice corrosion can happen in many locations including riveted, threaded, and welded areas. Nano-coating can be produced through dispersing the extremely tiny particles into the material surfaces to provide materials for strong anti-corrosion, durable material performance, and other super material physical properties[5,6]. The nanomaterial structure helps reducing the diffusive coefficient of liquids and gases to significantly trim down the corrosion process[7]. Researches on nanomaterial were advanced and promoted by the fact of considerable reduction of material corrosion by using nanotechnology.

\section{Anti-corrosion Mechanism of Nanocoated Materials}

* Corresponding author:

zhengli@bridgeport.edu (Jeremy Li)

Published online at http://journal.sapub.org/nn

Copyright (C) 2012 Scientific \& Academic Publishing. All Rights Reserved
The anti-corrosion mechanism of nanocoated materials can be illustrated by referencing the Fig. 1[8].

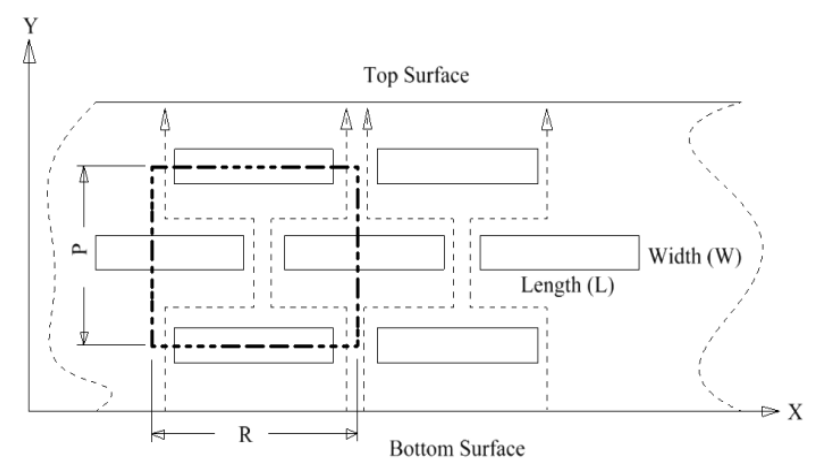

Figure 1. Illustrated diagram for diffusive molecules through nanocoated material

The structure of nanocoated thin layers performed as the barrier that causes the diffusive molecules moving around the barrier and makes it difficult for molecules to penetrate the coated layers[9]. Assume the travel distance of diffusive molecules changes from $S$ to $S$ ' due to the increase of travel inside barrier of nanocoated material and coefficient, $\lambda$ is the ratio of travel distance that diffusive molecules move across the coated layers with nano-coating and regular coating, and $\mathrm{M}_{0}$ and $\mathrm{M}$ are molecule diffusivities in nanocoated and regular coated material,

$$
\begin{gathered}
S^{\prime}=S+\frac{L}{2 * W} * \theta^{*} S \\
\lambda=\frac{S^{\prime}}{S}=\frac{S+\frac{L}{2 * W} * \theta^{*} S}{S}=1+\frac{L^{*} \theta}{2 * W}
\end{gathered}
$$




$$
\frac{M_{o}}{M}=1+\frac{\left(\frac{L}{W}\right)^{2} * \theta^{2}}{4 *(1-\theta)}
$$

Here, $\mathrm{L}$ and $\mathrm{W}$ are length and width defined in Fig. 1 and $\theta$ is volume fraction of nanocoated material. Equation (3) clearly shows that the aspect ratio $\mathrm{L} / \mathrm{W}$ and volume fraction $\theta$ control the relative diffusivity $\mathrm{M}_{0} / \mathrm{M}[10]$. Currently the nano-coating is an effective corrosion-resistant technology applied to many fields because of its superior corrosionpreventive property. Nanomaterial structure has its extremely small grain size and large grain boundary ratio with strong protective oxide scale that is firmly adhesive to the substrate of coated material with outstanding wear, scratchresistant, and water-resistant properties[11,12]. Nano- coating structure combines superior material strength and ductility. Environmental pollution can be reduced by applying nano-coating technology in comparison of current conventional coating technologies.

\section{Computer-aided Modeling and Simulation of Nano-Coating}

The computer-aided modeling and simulation tool developed in this research can assist us to understand the mechanism of corrosion process and reduction of material corrosion through nanotechnology.

Referencing Fig. 1, assume $\mathrm{N}_{0}$ and $\mathrm{N}$ the diffusive concentrations of molecules at the bottom and top surfaces for structural analysis (FEA) boundary conditions. The element dimension is $\mathrm{P} \times \mathrm{R}$. Applying all these parameters into the computer-aided modeling, the simulation results are shown in Figs. 2, 3 and 4. The Fig. 2 depicts the relation between molecule diffusivity ratio of $\mathrm{M}_{0} / \mathrm{M}$ vs. nano-coating element space $\mathrm{P} / 2$, under different volume fraction of nano-coating elements.

Fig. 3 shows the result of molecule fraction ratio of $\mathrm{Mo} / \mathrm{M}$ vs. volume fraction of nano-coating element.

Fig. 4 indicates the relation between coating delamination and experimental time.

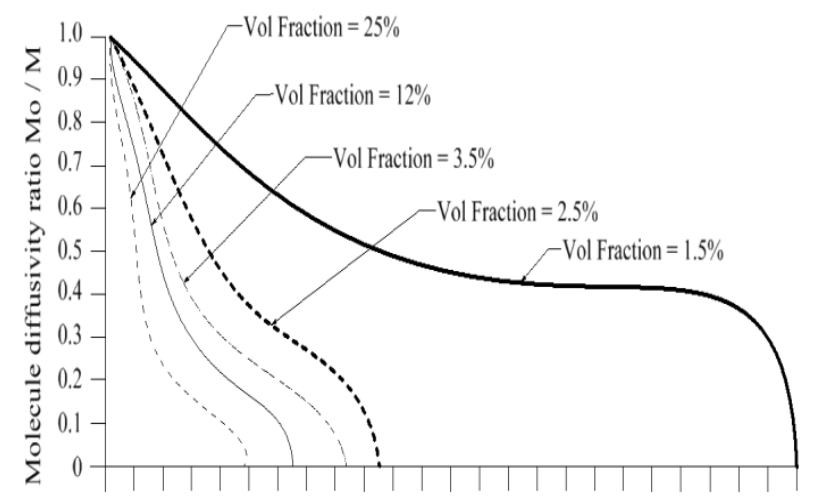

$0 \quad 5101520253035404550556065707580859095100105110115120$

$$
\text { Nano-coating element space } \mathrm{P} / 2(\mathrm{~nm}) \text { ) }
$$

Figure 2. Molecule diffusivity ratio of $\mathrm{M}_{0} / \mathrm{M}$ vs. nano-coating element space $\mathrm{P} / 2$

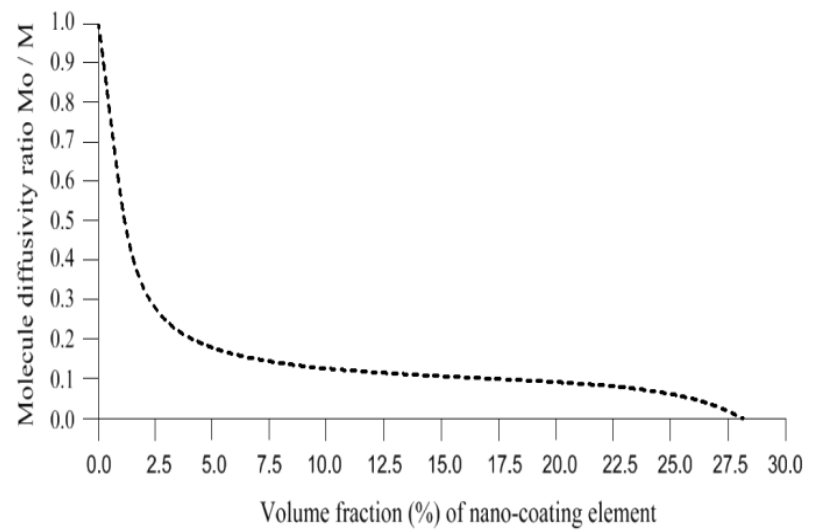

Figure 3. Molecule diffusivity ratio of $\mathrm{M}_{0} / \mathrm{M}$ vs. volume fraction of nano-coating element

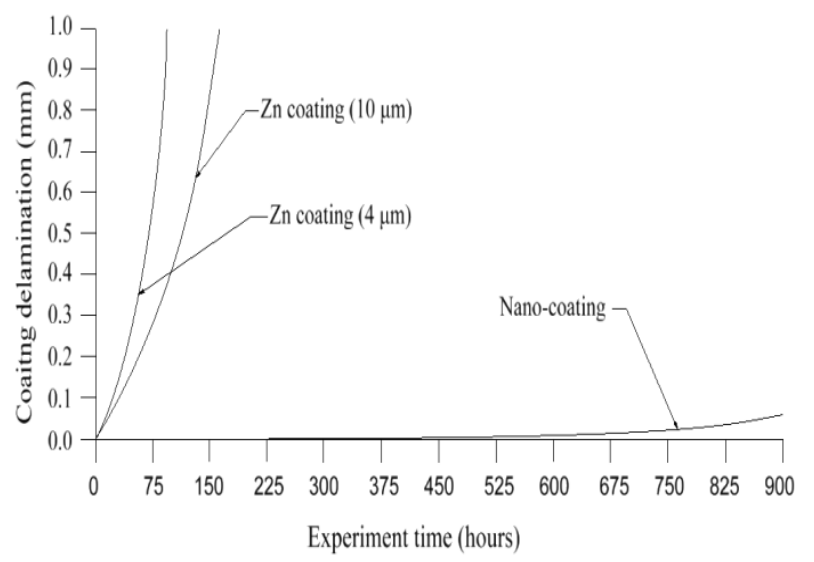

Figure 4. Coating delamination vs. sample experiment time

All the above computer-aided modeling and simulation confirm that the molecule diffusivity ratio $\mathrm{M}_{0} / \mathrm{M}$ is reduced when volume fraction of nano-coating is enhanced and the anti-corrosion performance of nanocoated product is much better than regular coated product including currently popular Zn coating.

\section{Sample Experiment}

Based on the testing standard of ASTM B117 and ASTM D1654, the sample tests have been performed to study and observe the performance of coatings subject to accelerated conditions in corrosion environment. The testing indicates significant improvement of anti-corrosion by using this nano-coating material which improves both stability of formed thin coating layer and kinetics of passive thin coating layer. The corrosion rate after applying this nano-coating is substantially reduced if compared with electro-galvanized coating. During testing, different grain sizes with 8-22 nm have been used in $5 \%$ sodium chloride solution. The smaller the grain size is, the larger the breakdown potential, passive current potential and aero current potential are. The dissolution (corrosion) rate is much lower in nano-coated material due to its enlarged breakdown potential and increased barrier to anodic dissolution from nano-coated material surfaces. Nano-coated material can be inspected for the physical and 
mechanical properties through X-ray diffraction technology and detected results show that the nano-coating deposits are produced in extremely small grain size. Material anti- corrosion performance relies on how efficient is the passive film developed, erosion extent of electrolyte, and property of electrode. In regular coating processes, the defect particles reside in the base metal materials, propagate through the coating film, and deposit in the grain boundary areas. In nano-coating process, the grain size is extremely small and grain number is significantly enlarged in which the defected particles are substantially diffused and evenly segregated which leads much stronger stress-resistant and corrosionresistant coating films.

The experiments have been performed on nano-coating and galvanized coatings to compare the results of computer-aided modeling and simulation. The testing results of molecule diffusivity ratio of $\mathrm{M} 0$ / $\mathrm{M}$ vs. nano-coating element space, molecule diffusivity ratio of M0/M vs. volume fraction of nano-coating element, and coating delamination vs. sample experiment time are shown in Tables 1, 2, and 3 respectively.

The experimental results show that the molecule diffusivity ratio $\mathrm{M}_{0} / \mathrm{M}$ will be decreased as volume fraction of nano-coating element is increased. Also the nano-coating has much superior anti-corrosion performance than the regular coating including $\mathrm{Zn}$ coating. All these experimental results are close to the computational simulation results introduced in this paper.

Table 1. Molecule diffusivity ratio $\mathrm{M}_{0} / \mathrm{M}$ vs. nano-coating element space $\mathrm{P} / 2$

\begin{tabular}{|c|c|c|c|c|c|}
\hline \multirow{2}{*}{$\begin{array}{c}\text { Nano-coating ele- } \\
\text { ment space P/2 (nm) }\end{array}$} & \multicolumn{5}{|c|}{ Molecule diffusivity ratio M0 /M } \\
\cline { 2 - 6 } & Vol. Fraction 1.5\% & Vol. Fraction 2.5\% & Vol. Fraction 3.5\% & Vol. Fraction 12.0\% & Vol. Fraction 25.0\% \\
\hline 0 & 1.00 & 1.00 & 1.00 & 1.00 & 1.00 \\
\hline 5 & 0.95 & 0.88 & 0.85 & 0.73 & 0.58 \\
\hline 10 & 0.86 & 0.71 & 0.55 & 0.43 & 0.23 \\
\hline 20 & 0.72 & 0.45 & 0.31 & 0.22 & 0.11 \\
\hline 30 & 0.62 & 0.35 & 0.22 & 0.12 & 0.00 \\
\hline 40 & 0.58 & 0.23 & 0.08 & 0.00 & 0.00 \\
\hline 50 & 0.52 & 0.00 & 0.00 & 0.00 & 0.00 \\
\hline 60 & 0.49 & 0.00 & 0.00 & 0.00 & 0.00 \\
\hline 70 & 0.47 & 0.00 & 0.00 & 0.00 & 0.00 \\
\hline 80 & 0.45 & 0.00 & 0.00 & 0.00 & 0.00 \\
\hline 90 & 0.41 & 0.00 & 0.00 & 0.00 & 0.00 \\
\hline 100 & 0.38 & 0.00 & 0.00 & 0.00 & 0.00 \\
\hline 110 & 0.35 & 0.00 & 0.00 & 0.00 & 0.00 \\
\hline
\end{tabular}

Table 2. Molecule diffusivity ratio $\mathrm{M}_{0} / \mathrm{M}$ vs. volume fraction of nano-coating element

\begin{tabular}{|c|c|}
\hline $\begin{array}{c}\text { Vol. fraction of nano-coating } \\
\text { element (\%) }\end{array}$ & $\begin{array}{c}\text { Molecule diffusivity ratio } \\
\mathrm{M}_{0} / \mathrm{M}\end{array}$ \\
\hline 0.0 & 1.00 \\
\hline 2.5 & 0.30 \\
\hline 5.0 & 0.22 \\
\hline 7.5 & 0.19 \\
\hline 10.0 & 0.17 \\
\hline 12.5 & 0.16 \\
\hline 15.0 & 0.14 \\
\hline 17.5 & 0.11 \\
\hline 20.0 & 0.10 \\
\hline 22.5 & 0.08 \\
\hline 25.0 & 0.05 \\
\hline 27.5 & 0.02 \\
\hline 30.0 & 0.00 \\
\hline
\end{tabular}

Table 3. Coating delamination vs. sample experimental time

\begin{tabular}{|c|c|c|c|}
\hline \multirow{2}{*}{$\begin{array}{c}\text { Experimental } \\
\text { time (hours) }\end{array}$} & \multicolumn{3}{|c|}{ Coating delamination length (mm) } \\
\cline { 2 - 4 } & Nano-coating & $\begin{array}{c}\text { Zn coating }(4 \\
\mu \mathrm{m})\end{array}$ & $\begin{array}{c}\text { Zn coating }(10 \\
\mu \mathrm{m})\end{array}$ \\
\hline 0 & 0.00 & 0.00 & 0.00 \\
\hline 25 & 0.00 & 0.08 & 0.05 \\
\hline 50 & 0.00 & 0.25 & 0.16 \\
\hline 75 & 0.00 & 0.98 & 0.35 \\
\hline 150 & 0.00 & 3.58 & 1.05 \\
\hline 225 & 0.00 & 5.56 & 1.88 \\
\hline 300 & 0.00 & 8.88 & 3.38 \\
\hline 375 & 0.00 & 12.5 & 5.78 \\
\hline 450 & 0.00 & 14.55 & 8.68 \\
\hline 525 & 0.00 & $>15.00$ & 9.85 \\
\hline 600 & 0.01 & $>15.00$ & 11.05 \\
\hline 675 & 0.03 & $>15.00$ & 12.45 \\
\hline 750 & 0.05 & $>15.00$ & 13.86 \\
\hline 825 & 0.08 & $>15.00$ & $>15.00$ \\
\hline 900 & 0.11 & $>15.00$ & $>15.00$ \\
\hline
\end{tabular}




\section{Conclusions}

This paper focuses on the study of mechanism of crevice corrosion and nano-coating performance based on computer-aided modeling and simulation to provide a fundamental understanding of anti-corrosion mechanism. The established computational model in this research can be used for further study and analysis on many different coating performances. The sampled crevice corrosions have been tested to verify the coating functionality. The computeraided simulation result well matches the sample testing result and both results show that the corrosion rate in nanocoated products is significantly reduced compared with regular $\mathrm{Zn}$ coated products. Also, molecule diffusivity ratio $\mathrm{M}_{0} / \mathrm{M}$ will be increased if the volume fraction of nano-coating element is decreased.

\section{REFERENCES}

[1] Chang, K., Park, D, Chang, H. and Ihn, K., "Exfloiated PA6.6 nanocomposites by modification with PA6", Journal of Polymer Science, 2001, Vol. 41, pp. 1514-1518.

[2] Zheludkevich, M., Serra, R., Montemor, M. and Ferreira, M., "Nanostructured sol-gel coatings depod with cerium nitrate as pre-treatments for AA2024-T3 corrosion protection performance", Journal of Electrochemistry, 2005, Vol. 5, pp. 208-217.

[3] Moggridge, N., Lape, C., Yang, W. and Cussier, E., "Barrier films using flakes and reactive additives", Proceeding of coating technology", 2003, Vol. 46, pp. 231-238.
[4] Sobolov, k. and Gutierrez, M., "How nanotechnology can change concrete world", Journal of Ceramic, 2005, Vol. 4, pp.14-17.

[5] Wang, Y., Limb, S., Luob, J. and Xub, Z., "Tribological and corrosion behaviors of $\mathrm{Al}_{2} \mathrm{O}_{3}$ polymer nanocomposite coatings", Journal of Wear, 2006, Vol. 2, pp.976-983.

[6] Guilemany, J., Dosta, S., Nin, J. and Miguel, J., "Study of the properties of WC-Co nanostructured coatings sprayed by high velocity oxy fuel", Journal of Thermal spray Technology, 2005, Vol. 14, pp. 405-413.

[7] Catledge, S., Fries, M and Vohra, Y., "Nanostructured surface modifications for biomedical implants, Journal of American Scientific Publications, 2004, pp.742-762.

[8] Carrado, K., "Polymer-clay nanocomposites in G.O. Shonaike and S.G Advani", Journal of Advanced Polymeric Materials, 2003, pp. 349-348.

[9] Youssef, K., Koch, C. and Fedkiw, P., "Improved corrosion behavior of nanocrystalline zinc produced by pulse-current electrodeposition”, Journal of Corrosion, 2004, Vol. 4, pp. 51-64.

[10] Shen, G., Chen, Y., Lin, L. and Scantlebury, D., "Study on a hydrophobic nano-Tio Coating an its properties for corrosion protection of metals", Journal of Electrochemistry, 2005, Vol. 5, pp. 5083-5089.

[11] Castro, Y., Ferrari, B., Moreno, R. and Duran, A., "Coatings produced by electrophoretic deposition from nano-particulate silica sol-gel suspensions", Journal of Surface Coating Technology, 2004, Vol. 182, pp. 199-203.

[12] Gao, W. and Li, Z., "Nanostructured alloy and composite coatings for high temperatures applications", Journal of Chemistry, 2004, Vol. 7, pp. 175-182. 